\title{
The effect of growth rate on reproductive outcomes in replacement dairy heifers in seasonally calving, pasture-based systems
}

\author{
C. J. Hayes,${ }^{1 *}$ C. G. McAloon, ${ }^{1}$ C. I. Carty, ${ }^{1}$ E. G. Ryan, ${ }^{1}$ J. F. Mee,${ }^{2}$ and L. $0{ }^{\prime}$ Grady ${ }^{1}$ \\ ${ }^{1}$ University College Dublin, Belfield, Dublin 4, Ireland D04V1W8 \\ ${ }^{2}$ Teagasc, Dairy Production Research Department, Dairy Production Research Centre, Moorepark, Fermoy, Co. Cork, Ireland P61C996
}

\section{ABSTRACT}

The effect of average daily gain (ADG) on reproductive outcomes in replacement dairy heifers was investigated. All heifers were managed in the typical Irish spring calving, pasture-based system, where the herd calves in 1 block between January and April and the majority of the diet comprises grazed grass. Heifer calves $(\mathrm{n}=399)$ from 7 herds were weighed at birth and at the beginning of the breeding season, and ADG was calculated. Service dates and pregnancy diagnosis results were recorded, and conception dates were calculated. Days open (DO) was defined as the number of days between the beginning of the breeding season and conception. Genetic data were retrieved from the Irish Cattle Breeding Federation database. A Cox proportional hazard model was constructed to identify variables with a significant effect on DO. An accelerated failure time model was used to predict survival curves and median survival times for different combinations of the significant variables. The ADG ranged from 0.41 to $0.91 \mathrm{~kg} / \mathrm{d}$, with a median of $0.70 \mathrm{~kg} / \mathrm{d}$. Frailty effect of farm within year, maintenance subindex of the economic breeding index, and ADG had a significant effect on DO. Derived from the final accelerated failure time model, the predicted median DO for a heifer with an ADG of $0.40,0.70$, or $0.90 \mathrm{~kg} / \mathrm{d}$ aged $443 \mathrm{~d}$ at the beginning of the breeding season and with a maintenance subindex in the second tercile were 27,16 , and $11 \mathrm{~d}$, respectively.

Key words: average daily gain, dairy heifer, reproduction, age at first calving, seasonal system

\section{INTRODUCTION}

Good reproductive performance is vital to any dairy system, and the maintenance of an appropriate calving to conception interval is essential for the supply of the

Received November 30, 2018.

Accepted February 24, 2019.

*Corresponding author: ciarahayes7587@gmail.com required volumes of milk at the time of year dictated by the system. The timing of calving of heifers is critical to maintenance of the compact calving pattern required by seasonal systems. These heifers, unhindered by the metabolic demands of milk production, can be expected to have high conception rates and calve early in the year, thereby bringing the mean calving date of the herd forward. Earlier calving provides an opportunity for more DIM and associated increased yearly milk yield, assuming the whole herd is dried off on a similar date, as is common practice in a seasonal system. The benefits of reducing age at first calving (AFC) have been widely demonstrated (Tozer and Heinrichs, 2001; Ettema and Santos, 2004; Eastham et al., 2018). The target AFC of 22 to 24 mo proposed by Akins (2016) may be achieved if live weight milestones of $55 \%$ of mature BW at breeding and $82 \%$ postcalving (NRC, 2001) are reached. For a typical Irish Holstein Friesian (HF) calf with a birth weight of $36 \mathrm{~kg}$ and a mature BW of $580 \mathrm{~kg}$ (Kennedy and Murphy, 2017), an ADG of $0.68 \mathrm{~kg} / \mathrm{d}$ would be necessary to reach these AFC and live weight targets.

In a seasonally calving system, the date of the first day of the breeding season predetermines minimal heifer age at breeding. With breeding beginning on a set date (termed mating start date; MSD) rather than when the individual has reached target weight, heifers have a fixed amount of time (birth to MSD and MSD to conception) in which to meet live weight targets. Heifers that fail to conceive in time to calve in their second year of life are then either left to calve at $3 \mathrm{yr}$ of age or removed from the herd (Berry and Cromie, 2009). The cost of rearing a dairy heifer to calve at $2 \mathrm{yr}$ of age is estimated at $€ 1,500$ (Shalloo et al., 2014). Calving at 36 mo extends the nonproductive life stage of the animal by $1 \mathrm{yr}$, further increasing the cost of rearing. The number of animals failing to achieve the target AFC must therefore be minimized to achieve economic efficiency. However, an Irish study has demonstrated a median AFC of 25 mo (Berry and Cromie, 2009), a full month later than the suggested target range. Data collected by the Irish Cattle Breeding Federation indicate 
that, of heifers that calved in 2018, only $70 \%$ calved between 22 and 26 mo of age (ICBF, 2018). This suggests that there is progress to be made in achieving target AFC in the Irish national dairy herd.

An AFC of greater than 24 mo is associated with reduced economic gain due to increased rearing costs despite increased revenue from greater first-lactation milk yield (Pirlo et al., 2000). It has also been linked with increased calving interval and increased firstlactation SCC (Eastham et al., 2018). Conversely, a much younger AFC of 21 mo has been shown to result in reduced first-lactation milk yield (Eastham et al., 2018). A meta-analysis by Zanton and Heinrichs (2005) demonstrated that prepubertal growth rates greater than $0.799 \mathrm{~kg} / \mathrm{d}$ resulted in reduced first-lactation milk production. Excessive growth rates can lead to obesity with the associated risks of dystocia (Hoffman et al., 1996) and transition cow disease (Mulligan et al., 2006). However, calves with low growth rates of between 0.40 and $0.56 \mathrm{~kg} / \mathrm{d}$ have been found to be older at puberty (Davis Rincker et al., 2011) and calving (Raeth-Knight et al., 2009) and have reduced mammary parenchyma in the prepubertal period (Brown et al., 2005). Onset of puberty, obviously a prerequisite for successful conception, has been consistently shown to be influenced by live weight more so than age. The attainment of 55 to $60 \%$ of mature $\mathrm{BW}$ has been demonstrated to be key for puberty to commence (NRC, 2001).

Limited published work is available on the rate of growth of calves in seasonally calving, pasture-based systems and its effect on their fertility. To the authors' knowledge, Macdonald et al. (2005) and Roche et al. (2015) are the only publications pertaining to this dairy system. As such, it is difficult to advise farmers about the optimal growth rate to aim for between birth and breeding to maximize heifer fertility. The aim of this study was to document growth rates in replacement dairy heifer calves on a selection of Irish farms and to investigate the effect and relative importance of growth rate on reproductive performance.

\section{MATERIALS AND METHODS}

The data used in this study were sourced from a convenience sample of 7 commercial spring-calving, pasture-based dairy farms in counties Kildare and Wicklow in Ireland. These farms were involved in an ongoing herd health management program conducted by University College Dublin (Somers et al., 2015; Šavc et al., 2016). Data were sourced from 434 heifers born in spring 2015 (7 herds) and 2016 (3 herds) and span the period from birth until the end of their first breeding season (i.e., July 2016 and 2017, respectively).
Nutritional management practices were not standardized across the farms and are summarized in Appendix Table A1. Reproductive management on all farms was via AI to observed estrus. Artificial insemination was replaced by natural service at a certain number of weeks (varying according to farm) into the breeding season. Reproductive hormonal treatments were not used as a routine management practice.

\section{Data}

Fertility Data. The first day of each breeding season, MSD, was reported by the farmer. The end of the breeding season was taken as the last recorded service date. Pregnancy diagnosis was carried out by ultrasound examination at approximately $30 \mathrm{~d}$ from last recorded service and again at approximately $60 \mathrm{~d}$ in gestation. Date of first service, date of conception, and pregnancy status at the end of the breeding season were recorded for each animal.

Weight Data. All weights were recorded by farmers using their own calibrated electronic weighbridge scales. Weight data were available for 434 calves. The mean number of weights per calf from birth to $2 \mathrm{yr}$ of age was $5.43(\mathrm{SD}=2.91)$, and $79 \%$ of all birth weights were taken on the day of birth. Calves $(\mathrm{n}=35)$ were excluded from the study if the initial weight was not taken within $10 \mathrm{~d}$ of age or when only one weight was available in the first year of life. Where not directly available, live weight $(\mathrm{kg})$ at birth and at MSD was estimated by fitting individual growth curves based on the method in Berry et al. (2005) using the von Bertalanffy (1957) growth curve function and minimizing the root mean squared error of actual versus fitted live weight using the Levenberg-Marquardt algorithm implemented in the $\mathrm{R}$ package minpak (Elzhov et al., 2016). The von Bertalanffy function is described as

$$
\mathrm{W}_{\mathrm{t}}=\mathrm{A}\left(1-\mathrm{Be}^{-\mathrm{kt}}\right)^{3} \text {, }
$$

where $\mathrm{W}_{\mathrm{t}}=$ live weight at age $\mathrm{t}$ (days); $\mathrm{A}=$ asymptotic mature live weight; $\mathrm{Be}=$ constant of integration; and $\mathrm{k}=$ maturing rate (per day). Mature weight was based on the function described by McParland et al. (2017):

mature live weight $=633.2-4.16 \times$ maintenance SI,

where maintenance SI = maintenance subindex of the Irish Economic Breeding Index (Veerkamp et al., 2002). Mean mature weight based on MSI was $588 \mathrm{~kg}$. Mean $\mathrm{A}, \mathrm{Be}, \mathrm{k}$, and root mean squared error were $551 \mathrm{~kg}$, $0.60,0.0035$, and $5.4 \mathrm{~kg}$, respectively. These values were comparable with those of Berry et al. (2005). 
Breed and Genetic Data. For each animal, overall economic breeding index (EBI; Veerkamp et al., 2002) as well as its subindices for production, fertility, calving, beef, maintenance, and health were obtained from the Irish Cattle Breeding Federation database. Predicted transmitting ability values for milk, fat and protein in kilograms, fat and protein percentage, calving interval, and survival were also collected. Calf breeds comprised a mix of HF, Friesian, and Jersey. Calves were categorized as either HF or Jersey crossbred. Crossbred animals were classified as having more than $40 \%$ Jersey genetics, and the remainder were classified as HF.

\section{Heifer Management}

Management practices were not standardized across the farms. To describe the management practices, information was collected via face-to-face interview and recorded using a standardized questionnaire.

\section{Statistical Analysis}

Variables. Data management was conducted in RStudio (RStudio Team, 2016). For each animal, the variables included in the data analysis were as follows: farm, breed, month of birth, MSD, end of breeding date, birth weight, weight at MSD, ADG from birth to MSD, estimated mature weight, percentage of mature weight at MSD, pregnancy status at the end of the breeding season, EBI subindices, and PTA values.

Descriptive Analysis. For each herd, the mean and standard deviation were calculated for each of the available variables. Distributions of ADG from birth to MSD, age at MSD, days open (DO), and days from MSD to first service were plotted (Figures 1, 2, 3, and $4)$.

Survival Analysis. Survival analysis was performed to assess the effect of ADG from birth to MSD on DO (number of days between MSD and conception) and on days to first service (number of days between MSD

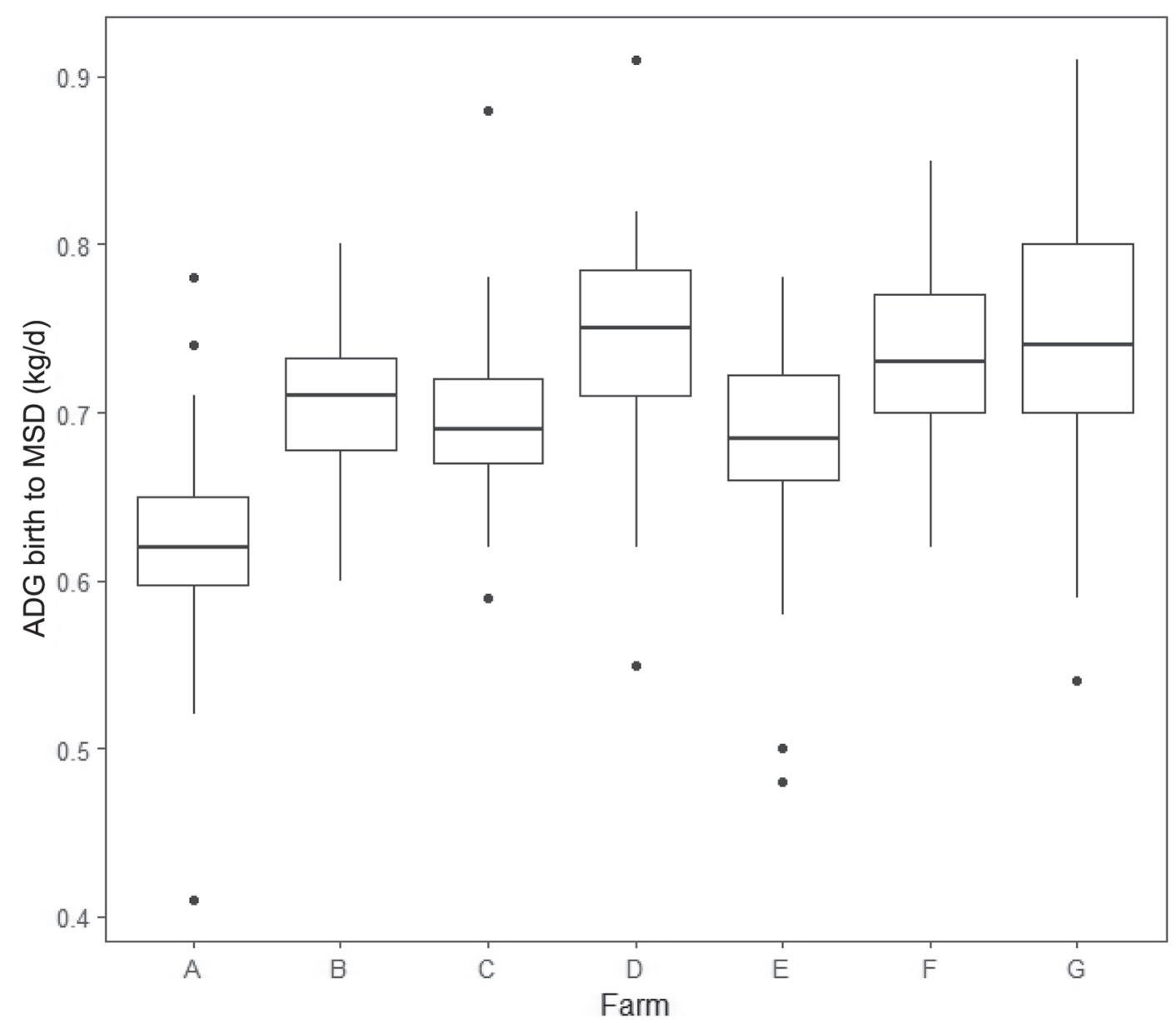

Figure 1. Boxplot demonstrating the distribution of ADG across 399 dairy heifers (2 yr of age) from 7 Irish herds. MSD = mating start date. Box $=$ interquartile range; midline $=$ median; whiskers $=1.5$ times the interquartile range; dots $=$ outliers. 
and first service) while accounting for genetic and phenotypic variables. All analysis was performed using the survival package in $\mathrm{R}$ (Therneau, 2015).

Cox Proportional Hazard Model. A Cox proportional hazard $(\mathbf{C P H})$ model was used to identify significant variables. Days open was used as survival time in the first model, and days to first service was used in the second. Pregnancy status at the end of the breeding season was used as the outcome event. Animals not pregnant at the end of the breeding season were right censored.

An initial univariate analysis was used to screen variables to be brought forward to the multivariate model building process. During the univariate and multivariate analyses, the frailty (random) effect of farm within year was included in all models. In addition, to account for the effect of differing ages at the start of breeding, age at MSD was included in all models. During the univariate analysis, log-log plots and examination of Schoenfeld residuals were used to evaluate the pro- portional hazards assumption. Maintenance subindex (MSI) of the EBI as a continuous variable showed significant time dependency of residuals. When grouped in terciles, the proportional hazards assumption was satisfied.

All variables significant at $P \leq 0.20$ were taken forward to multivariate analysis. A multivariate $\mathrm{CPH}$ model was constructed using a forward stepwise method with variables added in order of lowest univariate $P$-value. At each model-building step, variables were introduced and removed from the model based on a significant improvement $(P \leq 0.05)$ in a log-likelihood ratio test. Correlation between variables was assessed as variables were added to the model. If variables were correlated and resulted in nonsignificance when both were included, but the inclusion of either was significant individually, then the retained variable was selected by comparing the greatest improvement in likelihood ratio test $P$-value of the respective models. The hazard function for the derived model may be expressed as

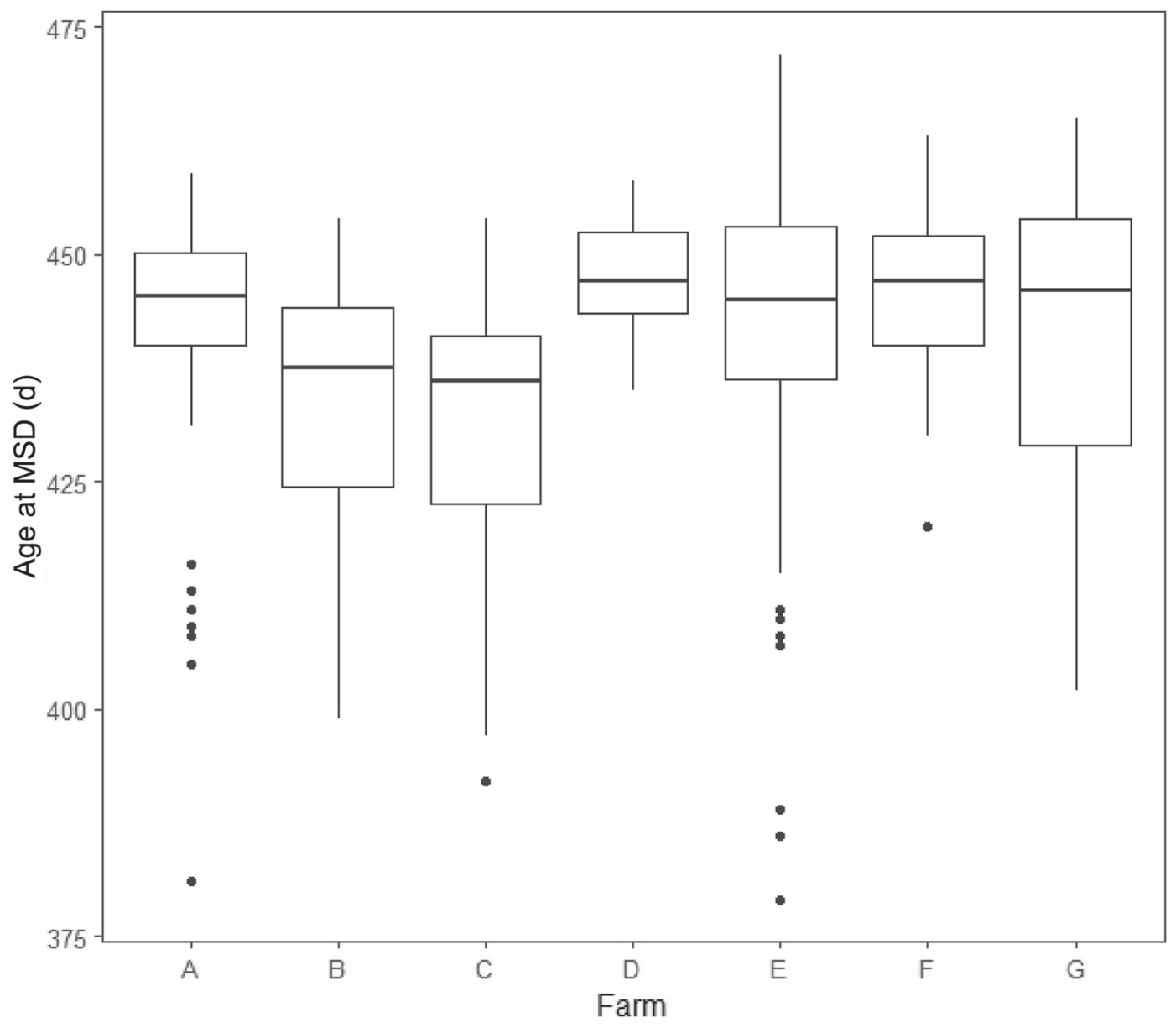

Figure 2. Boxplot demonstrating the distribution of age at mating start date (MSD) across 399 dairy heifers (2 yr of age) from 7 Irish herds. Box = interquartile range; midline = median; whiskers = 1.5 times the interquartile range; dots = outliers. 


$$
\lambda\left(\mathrm{t}_{\mathrm{ijk}} \mid \mathrm{Z}_{\mathrm{ijj}}\right)=\mathrm{Z}_{\mathrm{ij}} \lambda_{0}\left(\mathrm{t}_{\mathrm{ijk}}\right) \exp \left(\beta_{1} \mathrm{X}_{1 \mathrm{ijk}}+\beta_{2} \mathrm{X}_{2 \mathrm{ijk}}\right) \text {, }
$$

where $\lambda_{0}$ is the baseline hazard at time $\mathrm{t} ; \mathrm{Z}_{\mathrm{ij}}$ is the multiplicative frailty effect of the ith farm in the jth year; $\beta_{1}$ is the coefficient for ADG; and $\beta_{2}$ is the coefficient for MSI group where $\mathrm{X}$ is the respective covariate for cow k.

Accelerated Failure Time Model. To illustrate the relative importance of each of the parameters in the final $\mathrm{CPH}$ model, a parametric accelerated failure time model was used to predict survival functions of a range of combinations of the significant variables in the final CPH model. A range of distributions were trialed: Weibull, exponential, logistic, log-logistic, log-normal, and Gaussian. The final distribution was selected based on comparison of the Akaike information criterion values. The median and $90 \%$ survival times were predicted for several combinations of variable values.
RESULTS

\section{Descriptive Analysis}

After the exclusion of animals with missing live weights, 399 animals were included in the final data set. Summaries of the distribution of variables across each herd are shown in Table 1 and Figures 1, 2, 3, and 4 . Regarding breed, $85 \%$ of the calves were HF, with the remainder classified as crossbred. The ADG ranged from 0.41 to $0.91 \mathrm{~kg} / \mathrm{d}$, with a median of 0.70 $\mathrm{kg} / \mathrm{d}$ (interquartile range $=0.65-0.74 \mathrm{~kg} / \mathrm{d}$; Figure 1 ). Age at MSD ranged from 379 to $472 \mathrm{~d}$, with a median of $444 \mathrm{~d}$ (Figure 2). Of the heifers born in 2015 and 2016, $85 \%$ (235/276) and 85\% (104/123), respectively, conceived within 6 wk of MSD (i.e., had 42 or fewer DO). Figure 3 illustrates the distribution of DO across the 7 farms. Figure 4 illustrates the distribution of days to first service across the farms.

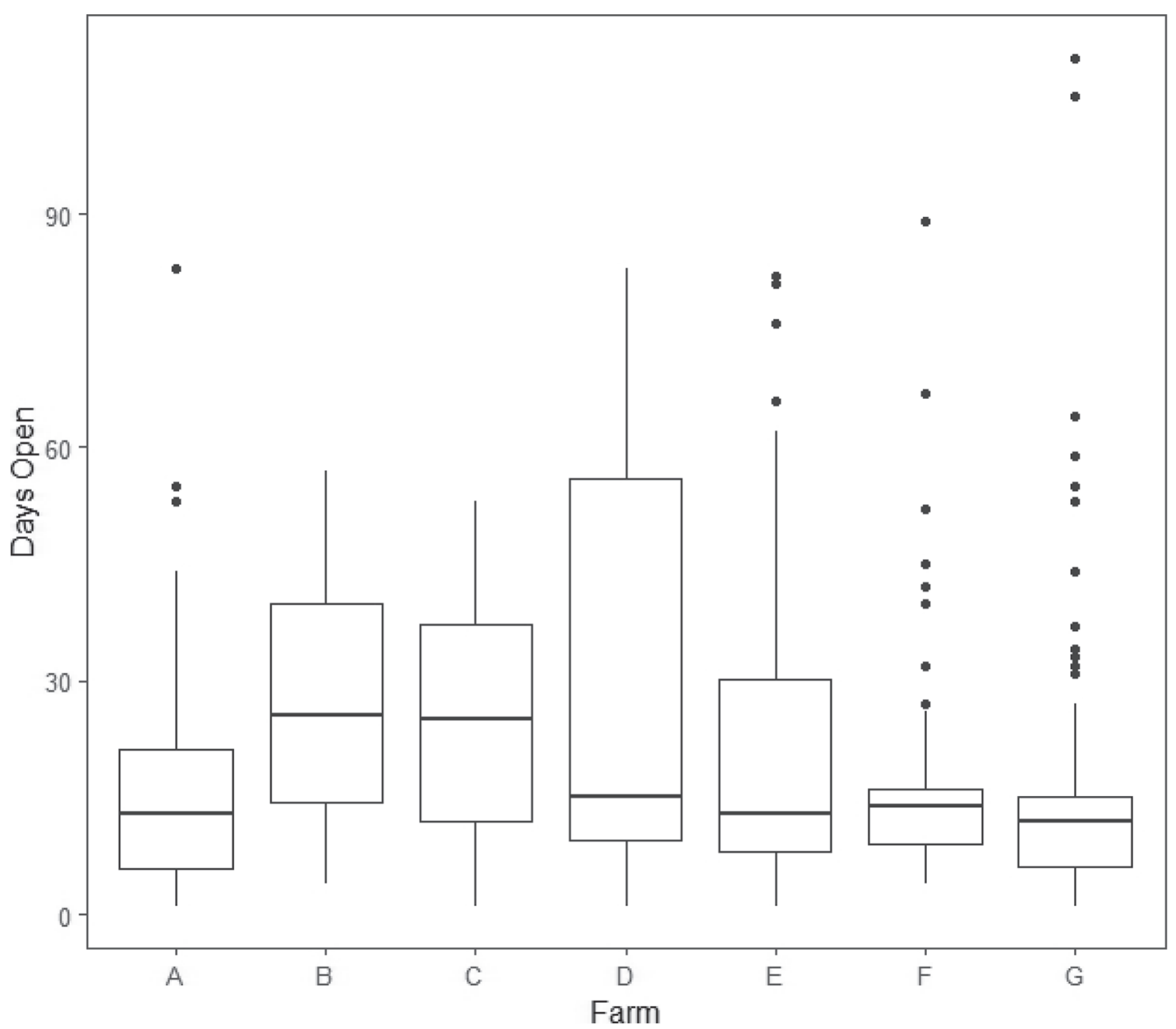

Figure 3. Boxplot demonstrating the distribution of days open across 399 dairy heifers (2 yr of age) from 7 Irish herds. Box $=$ interquartile range; midline $=$ median; whiskers $=1.5$ times the interquartile range; dots $=$ outliers. 


\section{Univariate Analysis}

DO Model. Following univariate analysis, age at MSD, MSI, breed, month of MSD, ADG, and fertility subindex of the EBI were taken forward for consideration in the DO multivariate model building process.

Days to First Service Model. For the corresponding days to first service model, age at MSD, percentage of mature weight at MSD, ADG from birth to MSD, breed, MSI, beef subindex, PTA for kilograms of milk fat, PTA for calf survival, and PTA for milk fat percentage were taken forward.

\section{Multivariate Analysis}

CPH Model: DO. Average daily gain as a continuous variable $(P=0.04)$, MSI categorized into terciles $(P=0.04)$, and frailty effect of farm within year $(P=$ 0.04 ) were all significant in the DO CPH model (Table
2 ). Age at MSD was retained but was not significant in the final model $(P=0.17)$.

CPH Model: Days to First Service. Percentage of mature BW at MSD was the only significant variable in the days to first service model $(P<0.01$; Table 3$)$. Frailty effect of farm within year was also included in this model $(P=0.19)$. Age at MSD, although retained, was not significant in the final model $(P=0.55)$.

Accelerated Failure Time Model. Predictions generated by the accelerated failure time model are demonstrated in Figure 5 and Table 4. Figure 5 displays cumulative hazard of pregnancy for a heifer with an age at MSD of $443 \mathrm{~d}$ and an MSI in the second tercile. The scale parameter for the shape of the log logistic curve was 0.58 . Predicted median DO for a heifer with an ADG of $0.40 \mathrm{~kg} / \mathrm{d}$ was $27 \mathrm{~d}$, dropping to $16 \mathrm{~d}$ with an ADG of $0.70 \mathrm{~kg} / \mathrm{d}$ and $11 \mathrm{~d}$ with an ADG of $0.90 \mathrm{~kg} / \mathrm{d}$. Predicted days until $90 \%$ chance of pregnancy for the same heifer were 103, 61 , and 43 for the same respective ADG.

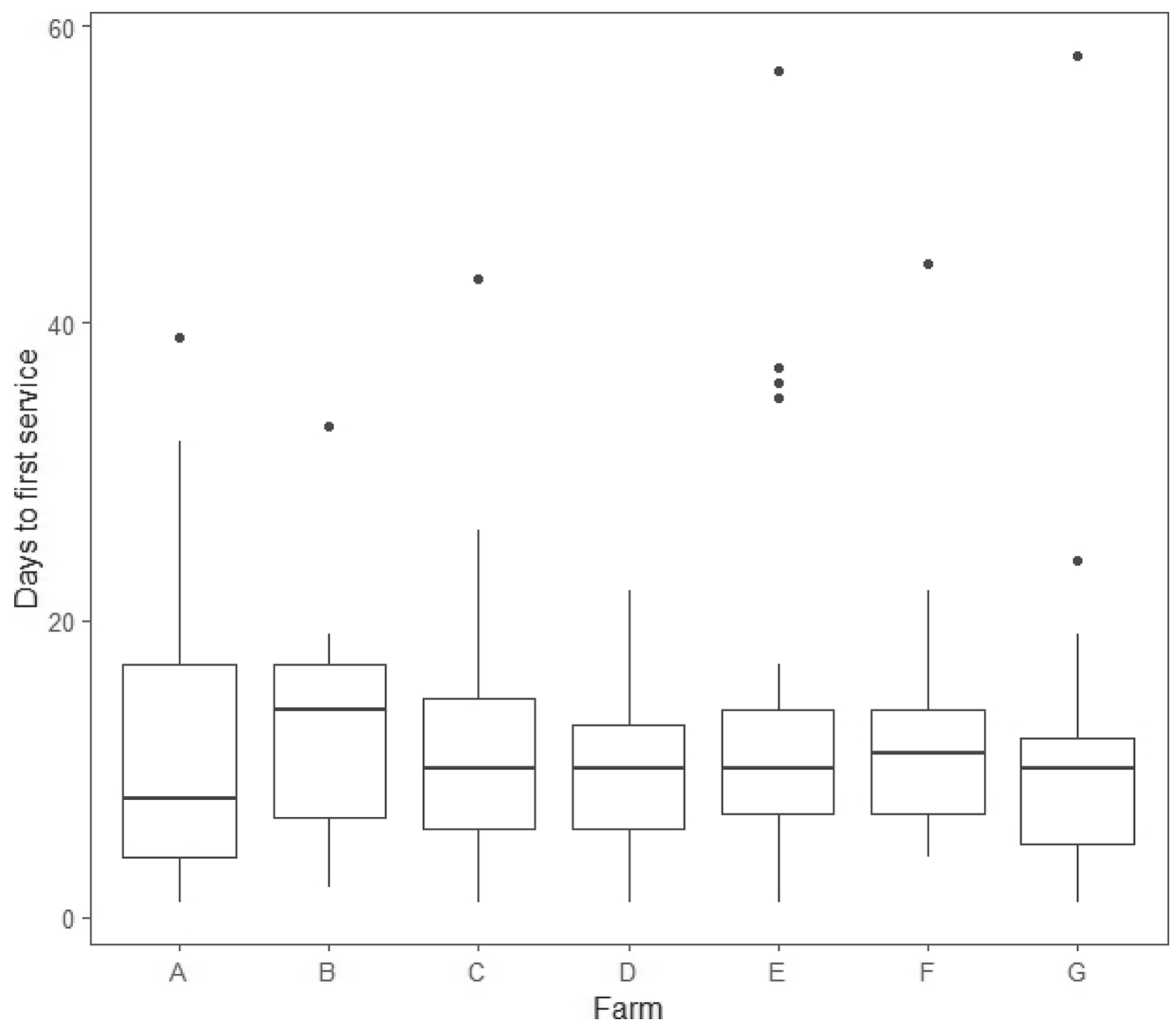

Figure 4. Boxplot demonstrating the distribution of days to first service across 399 dairy heifers (2 yr of age) from 7 Irish herds. Box $=$ interquartile range; midline $=$ median; whiskers $=1.5$ times the interquartile range; dots $=$ outliers . 


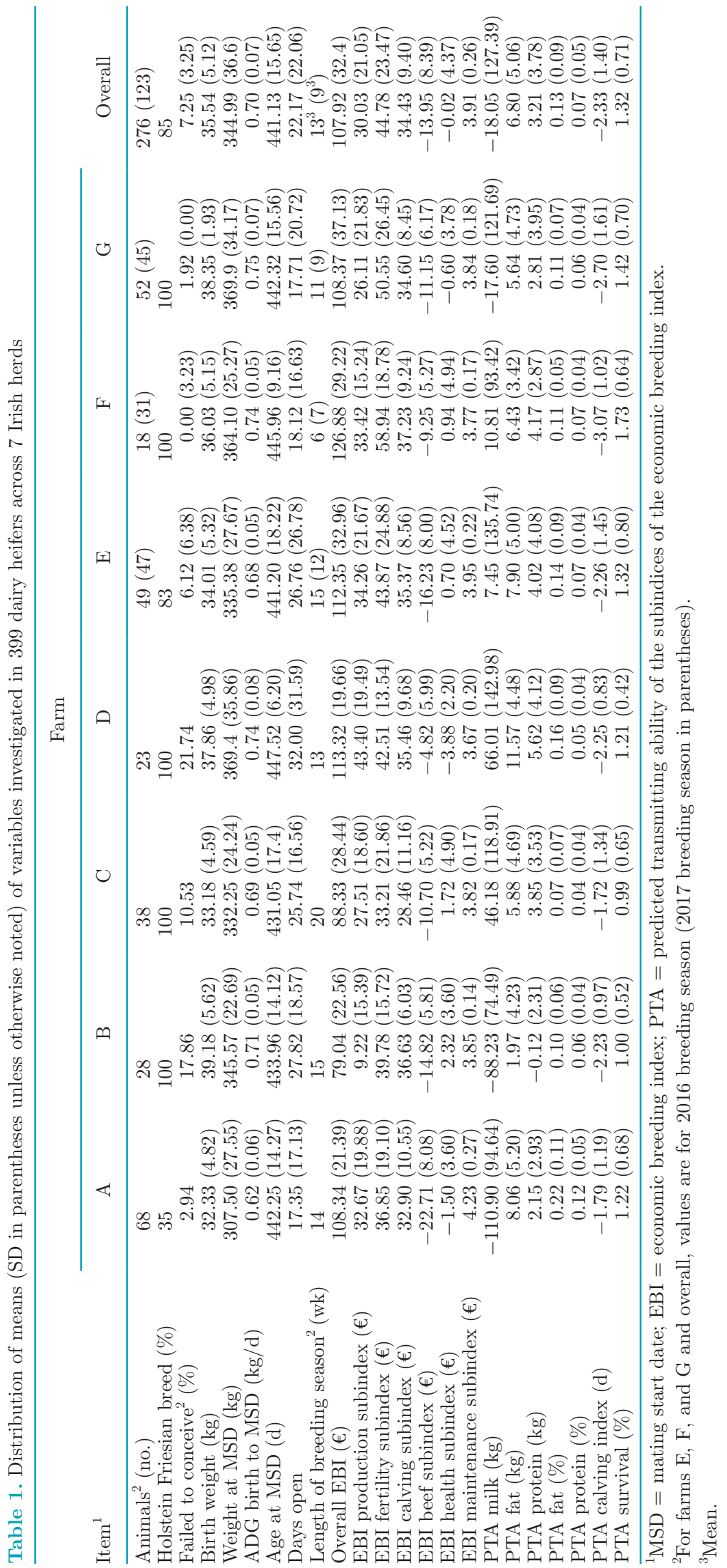


Table 2. Output from a Cox proportional hazard multivariate model with farm of origin within year of birth as random effects, demonstrating that ADG from birth to $\mathrm{MSD}^{1}$ and $\mathrm{MSI}^{2}$ has significant effects on the days open (i.e., number of days between MSD and conception) of 399 dairy heifers from 7 Irish herds ${ }^{3}$

\begin{tabular}{lccc}
\hline Variable & $\begin{array}{c}\text { Hazard } \\
\text { ratio }\end{array}$ & $\begin{array}{c}\text { Hazard ratio } \\
95 \% \text { CI }\end{array}$ & $P$-value \\
\hline Age at MSD & 1.01 & $1.00-1.02$ & 0.17 \\
ADG from birth to MSD & 6.99 & $1.13-43.02$ & 0.04 \\
MSI <5 & Referent & - & - \\
MSI 5-13 & 0.94 & $0.71-1.24$ & 0.66 \\
MSI $>13$ & 1.37 & $1.01-1.86$ & 0.04 \\
Farm within year & $0.08^{4}$ & - & 0.04
\end{tabular}

${ }^{1} \mathrm{MSD}=$ mating start date.

${ }^{2} \mathrm{MSI}=$ maintenance subindex of the economic breeding index.

${ }^{3}$ Age at MSD was forced into the model to account for the varying ages of the heifers at MSD.

${ }^{4}$ Variance of random effect.

\section{DISCUSSION}

\section{Methods and Study Data}

To the authors' knowledge, this is the first retrospective study to assess the effect of growth rate on fertility in pasture-based, seasonally calving dairy systems. Additionally, the authors are not aware of any similar studies using survival analysis to investigate this effect. Previous observational, retrospective research in this field (Brickell et al., 2009; Krpálková et al., 2014a,b) has been performed in the United Kingdom and the Czech Republic. In these countries, young stock spend less or no time at grass compared with the pasturebased system, which is most common in Ireland. Limited work has been published on the effect of growth rate on fertility in pasture-based dairy systems, where animals may not reach their growth potential due to variations in the availability and quality of grass (Roche et al., 2015). In New Zealand, Macdonald et al. (2005) imposed nutritional treatments on groups of HF and Jersey heifers, resulting in varying ADG,

Table 3. Output from a Cox proportional hazard multivariate model with farm of origin within year of birth as random effects, demonstrating that percentage of adult $\mathrm{BW}$ at $\mathrm{MSD}^{1}$ has a significant effect on the days to first service of 399 dairy heifers from 7 Irish herds ${ }^{2}$

\begin{tabular}{lccr}
\hline Variable & $\begin{array}{c}\text { Hazard } \\
\text { ratio }\end{array}$ & $\begin{array}{c}\text { Hazard ratio } \\
95 \% \text { CI }\end{array}$ & $P$-value \\
\hline Age at MSD & 1.00 & $0.99-1.01$ & 0.55 \\
Mature BW at MSD (\%) & 17.84 & $2.97-107.28$ & $>0.01$ \\
Farm within year & $0.08^{3}$ & - & 0.19 \\
\hline
\end{tabular}

${ }^{1} \mathrm{MSD}=$ mating start date.

${ }^{2}$ Age at MSD was forced into the model to account for the varying ages of the heifers at MSD.

${ }^{3}$ Variance of random effect. and assessed the effect of this variation on reproductive outcomes. This type of prospective, experimental study has previously been shown to yield different results compared with the retrospective, epidemiological study type described here when used to investigate the effects of growth rate in dairy heifers (Roche et al., 2015). Regression analysis and generalized linear modeling have previously been used to look at associations between ADG and reproductive parameters such as AFC, services per conception, conception rates, and calving interval (Krpálková et al., 2014a,b). The survival analysis performed in the current study is particularly suited to assessment of fertility in seasonally calving herds. The data provide a time element (DO, commencing at MSD) and an event (pregnancy), and the analysis can cope with censored data (heifers that reached the end of the breeding season without getting pregnant or that left the breeding herd during the season for a reason other than pregnancy, such as death).

\section{Modeling Outcomes}

Average daily gain, MSI of the EBI system, and farm within year of birth were all found to have a significant effect on DO in the multivariate model. The present study found that increasing ADG between birth and breeding reduces the number of days between MSD and conception (DO). For a heifer $443 \mathrm{~d}$ of age at the start of the breeding season, with an MSI in the second tercile, the median predicted DO were 27, 16 , and 11 for an ADG of $0.40,0.70$, and $0.90 \mathrm{~kg} / \mathrm{d}$, respectively. This clearly illustrates the reduction in DO with increasing ADG as well as the greater difference between the minimum and the median than between the maximum and the median, meaning that the beneficial effect declines as ADG increases. This reduction in DO translates to a reduction in herd-average AFC toward target, with the associated benefits not just in terms of maintenance of calving pattern but also with regard to survival in the herd (Sherwin et al., 2016), udder health (Eastham et al., 2018), lifetime milk yield (Pirlo et al., 2000), and economic returns (Tozer and Heinrichs, 2001; Ettema and Santos, 2004).

Several studies have previously examined the effect of ADG on various reproductive parameters. The only consensus, however, has been an association between increasing ADG in either the preweaning or prebreeding periods and a reduced age at puberty (Macdonald et al., 2005; Moallem et al., 2010; Davis Rincker et al., 2011) and first calving (Brickell et al., 2009; Raeth-Knight et al., 2009; Davis Rincker et al., 2011; Krpálková et al., 2014b). Increasing ADG has previously resulted in either no difference or a negative effect 


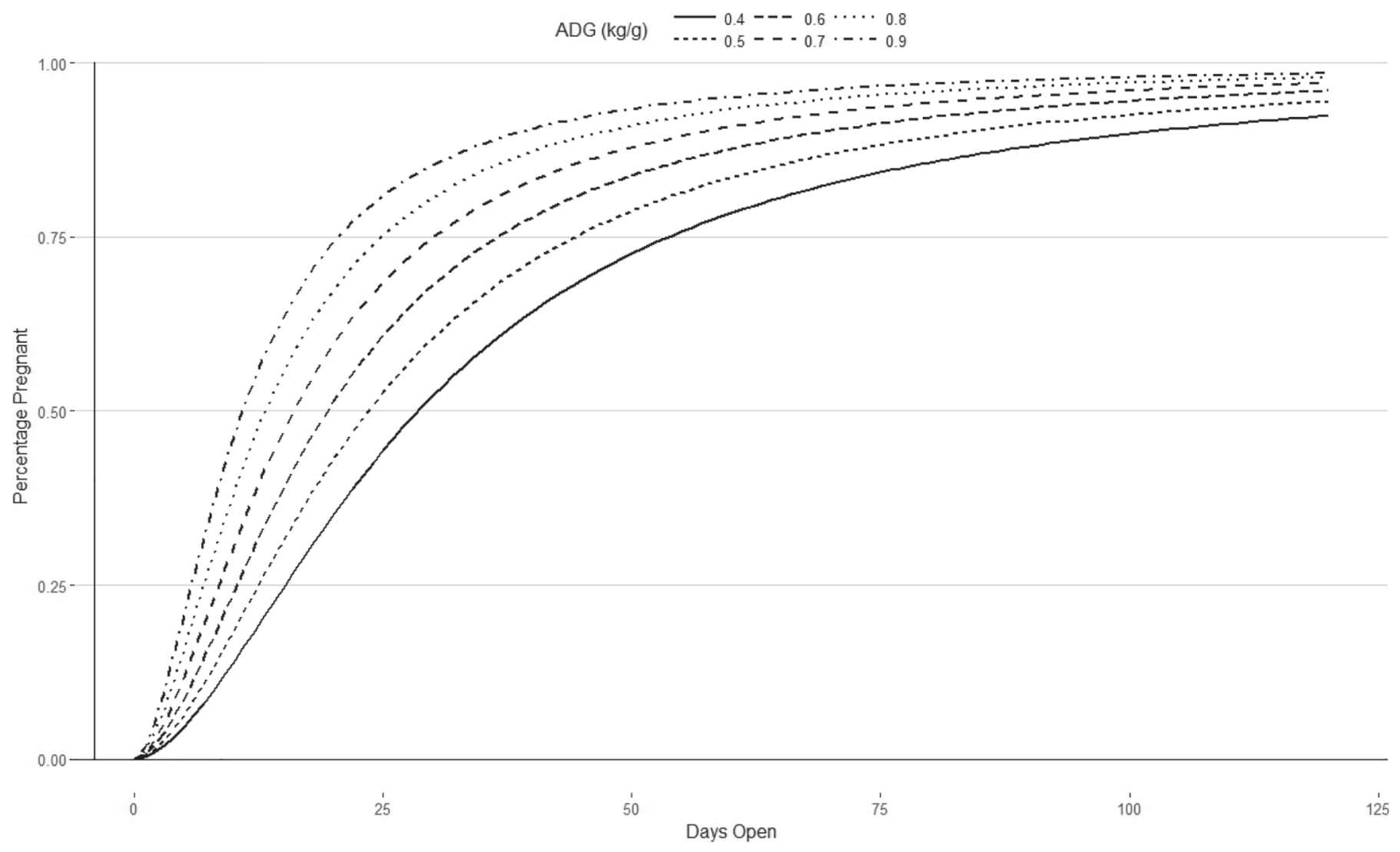

Figure 5. Predicted cumulative hazard of pregnancy demonstrating the effect of ADG from birth to mating start date (MSD) on days open (i.e., number of days between MSD and conception) for a heifer aged $443 \mathrm{~d}$ at MSD with a maintenance subindex of the economic breeding index in the second tercile.

on other measures of reproductive efficiency. Krpálková et al. (2014a) found that both conception rate to first service and overall conception rate in the first breeding season decreased with increasing ADG between 6 and 14 mo of age. In a separate publication, also by Krpálková et al. (2014b), a high ADG over a similar timeframe was associated with an increased interval between first and second calving. However, there were no significant differences in DO or services per conception between high-, medium-, and low-ADG groups. In contrast, Brickell et al. (2009) found that heifers with an increased growth rate from $30 \mathrm{~d}$ of age until breeding required more services per conception. These findings contradict those of the current study, which indicate that an increased ADG overall between birth and breeding has a positive effect on fertility. This

Table 4. Predictions from an accelerated failure time model demonstrating the effect of ADG from birth to $\mathrm{MSD}^{1}$ and $\mathrm{MSI}^{2}$ on the days open (DO; i.e., number of days between MSD and conception) of 399 dairy heifers from 7 Irish herds ${ }^{3}$

\begin{tabular}{|c|c|c|c|c|c|c|c|}
\hline \multicolumn{4}{|c|}{ Median DO } & \multicolumn{4}{|c|}{ Days to $90 \%$ chance of conception } \\
\hline 0.40 & 27 & 27 & 20 & 0.40 & 104 & 103 & 76 \\
\hline 0.50 & 23 & 23 & 16 & 0.50 & 87 & 87 & 64 \\
\hline 0.60 & 19 & 19 & 14 & 0.60 & 73 & 73 & 53 \\
\hline 0.70 & 16 & 16 & 11 & 0.70 & 61 & 61 & 45 \\
\hline 0.80 & 13 & 13 & 9 & 0.80 & 51 & 51 & 3 \\
\hline
\end{tabular}

${ }^{1} \mathrm{MSD}=$ mating start date.

${ }^{2} \mathrm{MSI}=$ maintenance subindex of the economic breeding index.

${ }^{3}$ Median DO (left) and number of days to $90 \%$ chance of conception (right) for various combinations of ADG and MSI for a heifer $443 \mathrm{~d}$ of age at MSD. 
could be due to differences in cow type and management system, this being the first observational study on this subject in a pasture-based system. Macdonald et al. (2005), whose study was performed on grazing heifers in New Zealand, found that varying growth rate between $100 \mathrm{~d}$ of age and puberty had no effect on days to conception. However, all heifers in the study were hormonally synchronized, which has an effect on this reproductive parameter and makes it difficult to compare directly with the findings of the present study. Difficulty in comparison with and between previous studies is further compounded by variation in the specific reproductive parameters used, differences in study design (observational vs. experimental), and the classification of high and low growth rates. For example, Krpálková et al. defined a high ADG as $\geq 0.95 \mathrm{~kg} / \mathrm{d}$ in one study (Krpálková et al., 2014b) and as $\geq 0.80 \mathrm{~kg} / \mathrm{d}$ in another (Krpálková et al., 2014a).

The MSI of the EBI system also had a significant effect on DO in the multivariate analysis. This figure is calculated from cull cow weight (Teagasc, 2014). It accounts for the fact that a larger cow will be more expensive to rear and maintain than one with a lower adult BW. As such, it is a genetic proxy for adult body size or mature live weight. As this is intrinsically linked to $\mathrm{ADG}$, it is unsurprising that it was significant in the final model.

The relationships and correlations between many of the variables investigated in this study can make it difficult to disentangle their effects. The significance of ADG, but not weight at MSD, in the DO model would appear to indicate that rate of growth toward a target actual BW is more important than simply reaching the target per se. Although percentage of mature BW at MSD, rather than ADG, was significant in the days to first service model, correlation exists between these 2 variables. Both models also reflect the importance of mature BW, either directly through MSI or through percentage of mature BW, which was calculated using MSI in our study. Although ADG should be considered in terms of mature BW, the model outcomes still indicate that a heifer that is heavier at mating benefits in terms of fertility. Additionally, there are inherent problems with how to define mature live weight (Roche et al., 2015), and this may not be possible on all farms, making use of the existing targets for proportion of mature BW (Troccon, 1993) difficult. In these cases, recommendations regarding ADG may be more broadly applicable.

The PTA for calving interval, which feeds into the EBI fertility subindex, did not have a significant effect on DO. This is in apparent contrast to Fenlon et al. (2017), who found it to be a significant predictor of conception rate. This difference may be due to the fact that the outcome in the present study was time to conception rather than conception to an individual service and the effect of ADG on the onset of puberty in heifers with its associated effect on submission rates. Previous studies have demonstrated the reduction in age at puberty associated with an increasing ADG (Macdonald et al., 2005; Moallem et al., 2010; Davis Rincker et al., 2011), BW being more important for puberty attainment than age (Archbold et al., 2012). It has also been shown that heifers are more fertile at their third estrus than at their first (Byerley et al., 1987). A greater ADG, resulting in earlier puberty, could ensure that heifers have had their earlier, less fertile estrus(es) before breeding.

Average daily gain was found to be heavily clustered according to farm. This is consistent with the data collected by Bazeley et al. (2016), who also reported significant farm-level clustering in growth rate. This is likely to be due to differences in management practices, which were not standardized across the farms. Genetics are also likely to have had an effect, with some farms rearing HF-Jersey cross calves and some rearing HF calves only. Where data were collected from the same farm over $2 \mathrm{yr}$, there was also significant clustering. This may reflect changes in management practices on the same farm from year to year, genetic variation between groups of calves, or the effects of weather on grass growth.

\section{Context in a Seasonal System}

Reduced DO means calving earlier in the year, which has economic benefits in terms of increased milk produced before dry off and maximization of grass utilization when cows are at peak yield (Shalloo et al., 2014). Calving for the first time early in the season also has a sustained effect throughout a cow's productive life, as a late-calving heifer is less likely to successfully breed in time to calve earlier in subsequent years. When considering the relative importance of each significant variable in the present study, the practicalities of altering these variables to effect a reduction in DO must be considered. The ADG is potentially an easily altered factor in the management of replacement heifers. Numerous research studies have produced alterations in heifer growth rate through nutritional management (Macdonald et al., 2005; Raeth-Knight et al., 2009; Davis Rincker et al., 2011). Seasonal calving also provides a cohort of calves all at similar ages and stages of growth, which makes manipulation of their diet to alter growth rate at different stages more achievable, though the evidence from this and other studies shows the wide variation in the actual growth rates achieved. 
Maintenance subindex provides a less immediate opportunity to bring forward a heifer's age at first conception. It is possible to achieve dramatic change in cow phenotype through genetic selection, as evidenced by the differences between the North American and New Zealand HF genetic strains (Berry et al., 2005). However, to achieve measureable change would take a minimum of $2 \mathrm{yr}$ before the genetically diverse animals enter the adult herd. The effect of MSI is currently not well understood, and it will take further investigation before it becomes a viable method of improving herd fertility. The farm-level clustering found highlights the importance of management on individual farms in achieving good reproductive performance.

Our study has demonstrated a statistically significant reproductive benefit to increasing ADG between birth and MSD in HF and Jersey crossbred heifers up to 0.91 $\mathrm{kg} / \mathrm{d}$. This finding can help facilitate the establishment of a target for prebreeding ADG in spring-calving, pasture-based systems. However, the interval between birth and first breeding covers a broad age range, and optimal ADG may vary according to stage of growth, an area that is outside the scope of this study. Maintaining a consistently high ADG of $0.91 \mathrm{~kg} / \mathrm{d}$ throughout this period may not be achievable or appropriate. Given the linear positive relationship between ADG and fertility, the optimal ADG will also be influenced by economics.

\section{Study Limitations and Future Work}

The farms used were a convenience sample rather than randomly selected, although they are typical of heifer rearing under Irish conditions. As such, the study was open to bias. The ADG figure reflects a continuous regular daily weight gain and does not take into account fluctuations in growth rate. Previous studies have demonstrated that altering growth rate at different stages of life can have an effect on a range of outcomes (Abeni et al., 2000; Macdonald et al., 2005), and optimal ADG may vary within the overall interval between birth and breeding. However, it was not within the scope of this study to investigate this effect. It is also unclear how much variation in outcome is due to short-term factors close to breeding rather than the long-term effect of ADG, although as much effort as possible has been made to account for confounding variables within the analysis.

\section{CONCLUSIONS}

Increasing ADG from birth to MSD results in reduced DO, leading to earlier calving and shortening the nonproductive life stage of the heifer. A linear positive effect was identified, but it was not possible within the bounds of this study to investigate the effect of ADG at different stages of growth within this period. Although these findings contribute to the establishment of targets for heifer ADG, it is not necessarily clear that it is appropriate to aim to maintain an ADG of $0.91 \mathrm{~kg} / \mathrm{d}$ consistently between birth and breeding. Further work will follow these heifers into first lactation and will look at the effect of ADG on both reproductive and lactation performance.

\section{ACKNOWLEDGMENTS}

The authors thank the Kildare Farmers' Group (Counties Kildare and Wicklow, Ireland), Mary Duane, Emmet Kelly, and Joris Somers (University College Dublin, Belfield, Dublin, Ireland) for their assistance with collection and collation of weight and fertility data.

\section{REFERENCES}

Abeni, F., L. Calamari, L. Stefanini, and G. Pirlo. 2000. Effects of daily gain in pre- and postpubertal replacement dairy heifers on body condition score, body size, metabolic profile, and future milk production. J. Dairy Sci. 83:1468-1478. https://doi.org/10.3168/ jds.S0022-0302(00)75019-3.

Akins, M. S. 2016. Dairy heifer development and nutrition management. Vet. Clin. North Am. Food Anim. Pract. 32:303-317. https: //doi.org/10.1016/j.cvfa.2016.01.004.

Archbold, H., L. Shalloo, E. Kennedy, K. M. Pierce, and F. Buckley. 2012. Influence of age, body weight and body condition score before mating start date on the pubertal rate of maiden HolsteinFriesian heifers and implications for subsequent cow performance and profitability. Animal 6:1143-1151. https://doi.org/10.1017/ S1751731111002692.

Bazeley, K. J., D. C. Barrett, P. D. Williams, and K. K. Reyher. 2016. Measuring the growth rate of UK dairy heifers to improve future productivity. Vet. J. 212:9-14. https://doi.org/10.1016/j.tvjl.2015 10.043 .

Berry, D., and A. Cromie. 2009. Associations between age at first calving and subsequent performance in Irish spring calving HolsteinFriesian dairy cows. Livest. Sci. 123:44-54.

Berry, D. P., B. Horan, and P. Dillon. 2005. Comparison of growth curves of three strains of female dairy cattle. Anim. Sci. 80:151160.

Brickell, J. S., N. Bourne, M. M. McGowan, and D. C. Wathes. 2009. Effect of growth and development during the rearing period on the subsequent fertility of nulliparous Holstein-Friesian heifers. Theriogenology 72:408-416. https://doi.org/10.1016/j.theriogenology 2009.03.015.

Brown, E. G., M. VandeHaar, K. Daniels, J. Liesman, L. Chapin, J. Forrest, R. Akers, R. Pearson, and M. W. Nielsen. 2005. Effect of increasing energy and protein intake on mammary development in heifer calves. J. Dairy Sci. 88:595-603.

Byerley, D. J., R. Staigmiller, J. Berardinelli, and R. Short. 1987. Pregnancy rates of beef heifers bred either on puberal or third estrus. J. Anim. Sci. 65:645-650.

Davis Rincker, L. E., M. J. Vandehaar, C. A. Wolf, J. S. Liesman, L. T. Chapin, and M. S. Weber Nielsen. 2011. Effect of intensified feeding of heifer calves on growth, pubertal age, calving age, milk yield, and economics. J. Dairy Sci. 94:3554-3567. https://doi.org/ $10.3168 /$ jds.2010-3923.

Eastham, N. T., A. Coates, P. Cripps, H. Richardson, R. Smith, and G. Oikonomou. 2018. Associations between age at first calving and subsequent lactation performance in UK Holstein and Holstein- 
Friesian dairy cows. PLoS One 13:e0197764. https://doi.org/10 .1371/journal.pone.0197764.

Elzhov, T. V., K. M. Mullen, A. Spiess, and B. Bolker. 2016. minpack.lm: R interface to the Levenberg-Marquardt nonlinear leastsquares algorithm found in MINPACK, plus support for bounds. $\mathrm{R}$ package version 1.2-1. Accessed Jan. 2018. https://CRAN.R -project.org/package=minpack.lm.

Ettema, J. F., and J. E. P. Santos. 2004. Impact of age at calving on lactation, reproduction, health, and income in first-parity Holsteins on commercial farms. J. Dairy Sci. 87:2730-2742.

Fenlon, C., L. O'Grady, M. L. Doherty, J. Dunnion, L. Shalloo, and S. T. Butler. 2017. The creation and evaluation of a model predicting the probability of conception in seasonal-calving, pasture-based dairy cows. J. Dairy Sci. 100:5550-5563.

Hoffman, P. C., N. M. Brehm, S. G. Price, and A. Prill-Adams. 1996. Effect of accelerated postpubertal growth and early calving on lactation performance of primiparous Holstein heifers. J. Dairy Sci. 79:2024-2031. https://doi.org/10.3168/jds.S0022-0302(96)76575 $-\mathrm{X}$.

ICBF. 2018. Dairy calving statistics 2008-2018. Accessed Nov. 30 2018. https://www.icbf.com/wp/wp-content/uploads/2018/09/ Dairy-Calving-Stats-2018-1.pdf.

Kennedy, E., and J. P. Murphy. 2017. Replacement heifers: Achieving target weight. Pages 156-157 in Proc. Moorepark '17 Irish Dairying-Resilient Technologies, Teagasc Moorepark.

Krpálková, L., V. E. Cabrera, J. Kvapilik, J. Burdych, and P. Crump. 2014a. Associations between age at first calving, rearing average daily weight gain, herd milk yield and dairy herd production, reproduction, and profitability. J. Dairy Sci. 97:6573-6582. https:// doi.org/10.3168/jds.2013-7497.

Krpálková, L., V. E. Cabrera, M. Vacek, M. Stipkova, L. Stadnik, and P. Crump. 2014b. Effect of prepubertal and postpubertal growth and age at first calving on production and reproduction traits during the first 3 lactations in Holstein dairy cattle. J. Dairy Sci. 97:3017-3027. https://doi.org/10.3168/jds.2013-7419.

Macdonald, K. A., J. W. Penno, A. M. Bryant, and J. R. Roche. 2005. Effect of feeding level pre- and post-puberty and body weight at first calving on growth, milk production, and fertility in grazing dairy cows. J. Dairy Sci. 88:3363-3375. https://doi.org/10.3168/ jds.S0022-0302(05)73020-4.

McParland, S., G. Ramsbottom, A. Cromie, J. McCarthy, K. Downing, and D. Berry. 2017. The EBI and its component traits translate into improved performance. Pages 77-78 in Proc. Moorepark ' 17 Irish Dairying-Resilient Technologies, Teagasc Moorepark.

Moallem, U., D. Werner, H. Lehrer, M. Zachut, L. Livshitz, S. Yakoby, and A. Shamay. 2010. Long-term effects of ad libitum whole milk prior to weaning and prepubertal protein supplementation on skeletal growth rate and first-lactation milk production. J. Dairy Sci. 93:2639-2650. https://doi.org/10.3168/jds.2009-3007.

Mulligan, F. J., L. O'Grady, D. A. Rice, and M. L. Doherty. 2006. A herd health approach to dairy cow nutrition and production diseases of the transition cow. Anim. Reprod. Sci. 96:331-353. https: //doi.org/10.1016/j.anireprosci.2006.08.011.

National Research Council. 2001. Nutrient Requirements of Dairy Cattle. 7th rev. ed. Natl. Acad. Press, Washington, DC.
Pirlo, G., F. Miglior, and M. Speroni. 2000. Effect of age at first calving on production traits and on difference between milk yield returns and rearing costs in Italian Holsteins. J. Dairy Sci. 83:603-608.

Raeth-Knight, M., H. Chester-Jones, S. Hayes, J. Linn, R. Larson, D. Ziegler, B. Ziegler, and N. Broadwater. 2009. Impact of conventional or intensive milk replacer programs on Holstein heifer performance through six months of age and during first lactation. J. Dairy Sci. 92:799-809. https://doi.org/10.3168/jds.2008-1470.

Roche, J. R., N. A. Dennis, K. A. Macdonald, C. V. C. Phyn, P. R Amer, R. R. White, and J. K. Drackley. 2015. Growth targets and rearing strategies for replacement heifers in pasture-based systems: A review. Anim. Prod. Sci. 55:902-915. https://doi.org/10.1071/ an14880.

RStudio Team. 2016. RStudio: Integrated Development for R. RStudio Inc., Boston, MA.

Šavc, M., M. Duane, L. E. O'Grady, J. R. Somers, and M. E. Beltman. 2016. Uterine disease and its effect on subsequent reproductive performance of dairy cattle: A comparison of two cow-side diagnostic methods. Theriogenology 86:1983-1988. https://doi.org/10 $.1016 / j$.theriogenology.2016.06.018.

Shalloo, L., A. Cromie, and N. McHugh. 2014. Effect of fertility on the economics of pasture-based dairy systems. Animal 8:222-231.

Sherwin, V. E., C. Hudson, A. Henderson, and M. J. Green. 2016. The association between age at first calving and survival of first lactation heifers within dairy herds. Animal 10:1877-1882.

Somers, J. R., J. Huxley, I. Lorenz, M. L. Doherty, and L. O'Grady. 2015. The effect of lameness before and during the breeding season on fertility in 10 pasture-based Irish dairy herds. Ir. Vet. J. 68:14. https://doi.org/10.1186/s13620-015-0043-4.

Teagasc. 2014. Understanding the economic breeding index. Accessed Nov. 30, 2018. https://www.teagasc.ie/media/website/animals/ dairy/Understanding_EBI_PTA_BV_Spring_2014.pdf.

Therneau, T. 2015. A package for survival analysis in S. R package version 2.38. Accessed Jan. 2018. https://CRAN.R-project.org/ package $=$ survival.

Tozer, P. R., and A. J. Heinrichs. 2001. What affects the costs of raising replacement dairy heifers: A multiple-component analysis. J. Dairy Sci. 84:1836-1844. https://doi.org/10.3168/jds.S0022 $-0302(01) 74623-1$.

Troccon, J. 1993. Effects of winter feeding during the rearing period on performance and longevity in dairy cattle. Livest. Prod. Sci. $36: 157-176$

Veerkamp, R., P. Dillon, E. Kelly, A. Cromie, and A. Groen. 2002. Dairy cattle breeding objectives combining yield, survival and calving interval for pasture-based systems in Ireland under different milk quota scenarios. Livest. Prod. Sci. 76:137-151.

von Bertalanffy, L. 1957. Quantitative laws in metabolism and growth. Q. Rev. Biol. 32:217-231.

Zanton, G. I., and A. J. Heinrichs. 2005. Meta-analysis to assess effect of prepubertal average daily gain of Holstein heifers on firstlactation production. J. Dairy Sci. 88:3860-3867. https://doi.org/ 10.3168/jds.S0022-0302(05)73071-X. 


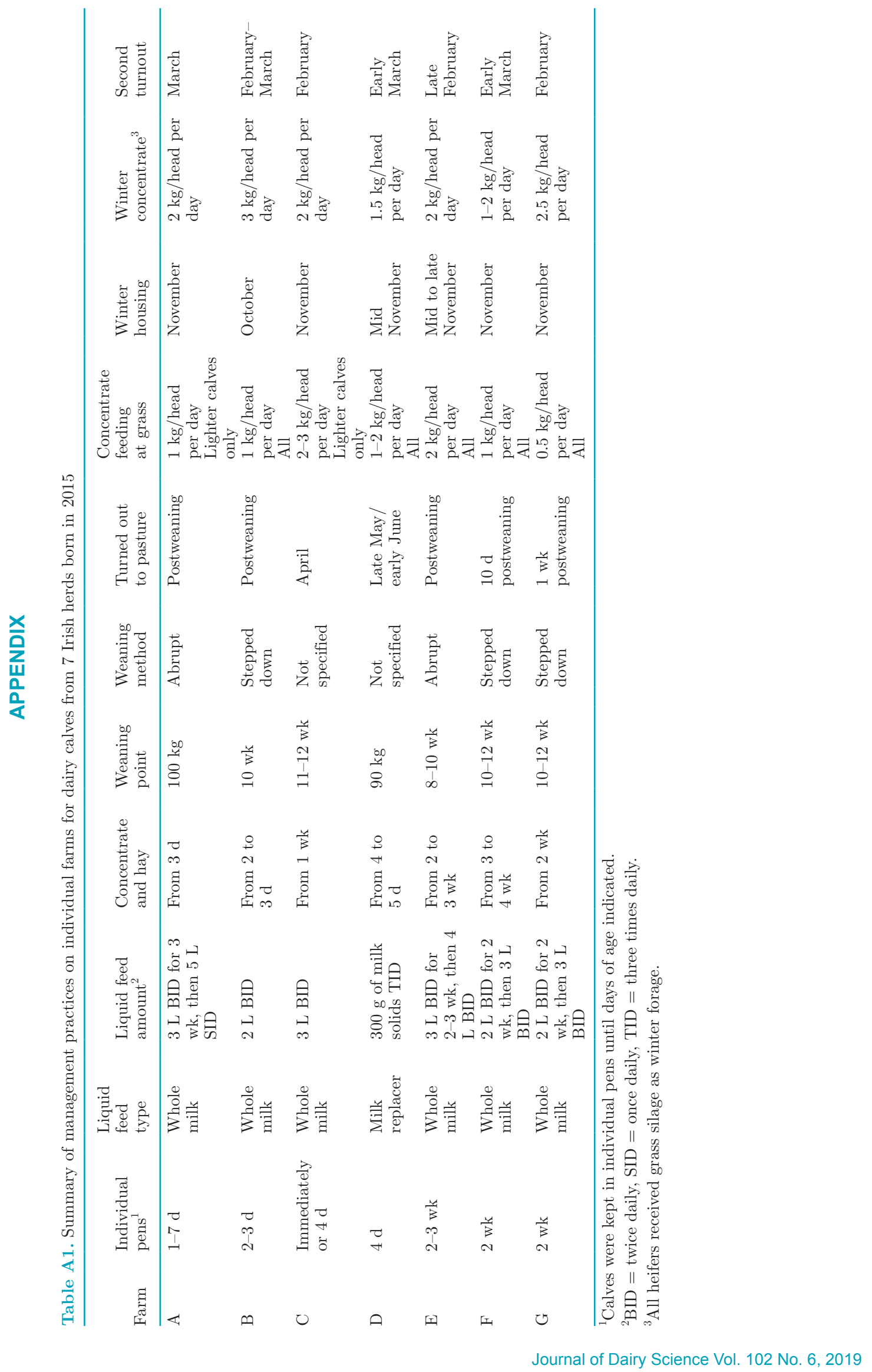

